\title{
The Comparison of Chinese and Western Marriages with Analysis on the Relevant Causes
}

\author{
Jingguang Li \\ Faculty of Foreign Languages \\ Huaiyin Institute of Technology \\ Huai'an, China 223003
}

\begin{abstract}
As we know, different countries have different cultures, and it is the different cultures that lead to the difference of the marriages in different nations. This thesis mainly talks about the differences of the marriage between China and the western countries from the following two aspects: marriage customs and marriage sense. For marriage customs, this thesis makes a detail explanation from such aspects as marriage color and wedding dress, marriage venue, marriage ceremony as well as marriage banquet. And for marriage sense, this thesis mainly gives an explicit illustration from these following different angles like the purpose to get married, the decision-making right for the marriage, the standard for choosing the spouse and the conjugal relationship in the marriage. On the basis of the above detailed instruction, this thesis makes an analysis on the reasons to bring about the difference between the Chinese marriage and the western marriage from the three aspects such as cultural and religious factors, cultural value factors and family environmental factors. Then the thesis further points out the tendency for the Chinese marriage and the western marriage to influence and integrate each other. Finally, it puts forward the viewpoint the marriage in the future will be convenient, colorful and individualized; most young men in the world must try their best to hold their elegant, romantic as well as very spectacular marriages with their imagination and the creativity.
\end{abstract}

Keywords-difference; the marriage customs; the marriage sense; causes; tendency

\section{INTRODUCTION}

As we have seen, marriage is the most important thing to all the persons in different cultures, which symbolizes a turning point of a person's life and the establishment of a new family. As a result, marriage has been emphasized by all the nations with different cultures, which confirms the diversity of the social customs in different cultures further. Starting with the comparison of the marriage ceremony between China and the western countries, this thesis will make a detail explication on different aspects of Chinese and western marriage, analyzing some relevant causes which lead to these differences as well. Through such a comparison and the corresponding analysis, we can achieve a further understanding about the social customs of different cultures in order for us to make a beneficial communication with the people from different cultural backgrounds, getting along well with each other.

\section{THE DIFFERENCE OF THE MARRIAGE CUSTOMS BETWEEN CHINA AND WESTERN COUNTRIES}

First of all, the differences between Chinese marriage and the Western marriage reflect in the aspect of the marriage customs. Because of the cultural difference, there are some conspicuous distinctions in the marriage customs between China and the western countries. To be specific, the differences are mainly displayed in the following aspects.

\section{A. Marriage Color and Wedding Dress}

In China, Red is the main color in the traditional marriage. On the wedding day, red lantern is often hung on the gate of the house, and the paper cutting with the red Chinese character “嗙” are put up on the windows. The bride with the red wedding dress and a red covering takes the red sedan to the bridegroom's home decorated with the red silk and the red couplets. The bridegroom also with the red groom suit and a red flower in front of his chest rides a horse with the bridal sedan following to his home or the wedding location. The wedding venue is also decorated with the red color to establish a kind of atmosphere of happiness and fervency.

In the western countries, white is usually the main color in the marriage. On the western wedding, the bride tends to wear the white marriage dress and the marriage house is usually decorated with the white color. As well, the young couples take the white bridal car to the wedding venue with the white wedding cake prepared. When the wedding is held in the garden and the garden is also decorated with the white or yellow flowers here and there to build up an atmosphere full of coziness, elegancy and romance.

\section{B. Marriage Venue}

Another difference of the marriage customs between China and the western countries lies in the wedding venues. In the past, the Chinese wedding used to be held in the bridegroom's house with one of the groom's friends or classmates hosting their wedding ceremony. Nowadays except for some rural areas, most wedding ceremonies are usually held in a larger restaurant where a special stage will be arranged on the wedding with a special host from the wedding company hosting the whole ceremony. 
However, the western wedding is often held in the church with a priest hosting the whole ceremony. While the young couples stand on the platform facing the audience, the priest will ask them respectively if he or she likes to stay or live with the other one forever whenever she or he become old, ill or poor in the future after the marriage witness makes a speech. Both the bride and the groom will make a definite reply. Sometimes, the western wedding is also held in the open air usually in the garden where an arch door or a stand will be set up with white or red flowers to establish an atmosphere of coziness and romance. When the wedding ceremony is nearly over, the bride will throw a bundle of flowers to the audience, it is said that the young person who gets such a bundle of flowers will be the next to get married and others will give the best wishes to him or her.

\section{Marriage Ceremony}

In the ancient China, the marriage ceremony mainly referred to three letters and six etiquettes. The Three Letters included the betrothal letter, the gift letter and the wedding letter, each of which was used in a different ritual of the marriage. And six etiquettes were made up of six procedures in the process of the whole marriage including Proposing Marriage, Matching Birthdates, Submitting Betrothal, Presenting Wedding Gifts, Selecting a Wedding Date and Holding a Wedding Ceremony.

On the morning of the wedding, the bride would be helped by a respectable old woman to tie up her hair with colorful cotton threads. Red was widely used as the lucky color, indicating fortune and happiness. When the bridegroom arrived, the bride, covered by a red headkerchief, usually cried in the face of her family members, showing the reluctance to leave home. Then, her elder brother would lead her to the sedan. Usually the groom would encounter a series of difficulties intentionally set on his path before he successfully handled it to be allowed to see his future wife. Upon the arrival of the sedan at the boy's residence, there would be music and firecrackers to create a merry atmosphere. The couple would be led along the red carpet, kowtowing three times to worship the heaven, parents and spouse. Then the new couple would go to their bridal chamber and the guests would be treated to a feast. On the night of the wedding day, a custom in some places was that the relatives or friends were supposed to banter the newlyweds to bring noisiness and scare off the evil spirits deliberately. On the third day of the marriage, the new couple would return to the bride's home, seeing the girl's parents and having a dinner with all the bride's relatives.

In the modern China, the marriage ceremony has undergone a series of evolution, which has become much more different from the traditional one. When the wedding day is coming, the young couples have began to be busy with making an adequate preparation for their marriage by obtaining the marriage certificate, taking the wedding photos, purchasing the marriage supplies and contacting the wedding company etc. On the wedding day, the bridegroom's parents usually invite lots of friends and relatives to have the dinner at home or in the large restaurants. The formal wedding ceremony is usually held by the host from a special wedding company. After a series of wedding procedures, the wedding banquet has begun with the friends and the guests talking and praising the bride's beauty or the bridegroom's handsomeness.

During the meal, the bride and groom will go from table to table to toast the guests sometimes accompanied by their parents or their best friends. The guests will also toast the bride and groom. In the end, the newly-weds and their parents will stand at the door, expressing their thanks to the guests as they leave.

Compared to Chinese marriage ceremony, the western marriage ceremony is much simpler but more solemn. The western wedding is usually held in the church or in the private garden with the priest hosting the whole wedding. When the guests arrive at the church, they will be greeted by the ushers, and the guests from the bride's and the groom's family will sit separately with the front rows usually reserved for family members and close friends. On that day, the bride tends to arrive at the church in elegant cars, limos, or sometimes carriages for a special effect. The bridal companion typically comprises the bride and her father, the bridesmaids, the maids of honor and the flower girl etc.

When the ceremony begins, the groom and his groomsmen stand with the minister on the platform, facing the audience. When the marriage music sounds, the bride who standing the entrance of the church will walks towards the platform very slowly, accompanied by her father, who will gives his daughter's hand to the lucky young man. Then the young couple begin to utter their vows, promising to love each other "for better, for worse, for richer, for poorer, in sickness and in health". But from time to time the young couples compose their own words. After that, they start to exchange the rings to symbolize their marriage commitment. Finally the minister announces the most important moment: "I now pronounce you have come the husband and wife. You may kiss the bride!"

After the ceremony, the bride and groom will go to a side room with the priest and two witnesses, signing the stateissued marriage license in the United States. In the United Kingdom, however, wedding register is usually signed before the weeding ceremony.

\section{Marriage Banquet}

The marriage banquet is regarded as the most important procedure in the whole ceremony both in China and in the western countries. However because of the different dieting habits, there are still lots of differences on the marriage banquets between the two different cultures. In China, the wedding banquet is still one of the major events in the whole wedding ceremony. Such a banquet is usually held in a large magnificent restaurant after the wedding with more than 12 courses served in most cases. All the guests are seated at the round tables, following the carefully-arranged seating chart to ensure that guests are seated with acquaintances who usually present the couple with monetary gifts. During the banquet, the young couple with their parents or best friend will propose the toast to all the guests at present by going 
from table to table and the guests will give the best wishes to the newly-married young couples.

Compared to the Chinese marriage banquet, the western wedding banquet looks simple and casual which usually takes the form of buffet dinner. Sometimes maybe there will be a ball following the wedding ceremony with the beautiful music. As well as the buffet, a big wedding cake is often offered in the wedding banquet. For all the guests at present, one of the most important activities is just to share the wedding cake, standing for enjoying the happiness together with the young couple. Besides as the symbol of the purity, the white wedding cake is also used as the dessert in the banquet. The whole wedding banquet is arranged by the bridal family, when it is nearly over, the guest will throw some bread crumbs to the bride, hoping that she will have a baby as early as possible.

\section{Difference In Marriage Sense Between China AND WESTERN COUNTRIES}

Generally speaking, there are some similarities of the marriage sense between China and western countries. For example, most people get married both in Chinese traditional culture and in the western culture just in order to find a lifelong spouse and form a stable family relationship for the couples to help and support each other in the marriage life. However, when it comes to some respective aspects such as the main purpose of marriage, the decision-making right in the marriage, the standard of choosing the spouse and the conjugal relationship, there are lots of differences.

\section{A. Purpose to Get Married}

According to most Chinese people, the main purpose to get married is just to generate the offsprings and carry on the family lineage. After all, the family takes on the supreme status in the Chinese traditional culture, which can be confirmed by a popular saying "There are three forms of unfilial conduct of which the worst is to have no descendents" among most Chinese people passed down from generation to generation. Even up to now, having a child especially having a boy is stilled regard as the most important function for the young couple to come together and it is looked on as the biggest expectation to most grandparents especially in the rural area. With the boy coming into a family, both his parents and his grandparents tend to be very happy, thinking it to be the most important thing in their lives and making a celebration by inviting their friends and relatives to have a dinner when the baby is one month or one hundred days old. As for most people in the western countries, there are the following reasons for them to get married. First, they want to have a satisfactory result for their love. Secondly, they are looking forward to finding a long-term partner to get satisfaction spiritually and physically; thirdly, Westerners are usually independent and self-oriented, so they regard marriage as the combination of two individuals that is based on love and sex only. In their perspective, marriage without love is unimaginable and unqualified.

\section{B. Decision-making Right in the Marriage}

In China, the most conspicuous characteristic in the marriage is that parents play an important role in making a decision on their children's marriage. In the ancient time, most Chinese people believed that their marriage should be dominated or decided by their parents and the children themselves had no right to make their own choice. Even today before the young people make a decision about their marriage, it is common for them to ask for their parents' approval; as far as they are concerned only when the marriage has been approved or blessed by their parents, will their coming family life be happy and harmonious.

When it comes to the decision-making right in the westerners' marriage, the case is much more different from that in China. In most young westerners' opinion, marriage is their own business and they have the right to make their own choice completely, some other persons even their parents have no right to interfere with it.

\section{Standard for Choosing the Spouse}

As for the standard of choosing the spouse, there is a large difference between China and the western countries because of the influence of different cultural factors. When most Chinese look for the spouse, what they tend to pay great attention to include the following aspects such as age, appearance, stature, family background, money, house, work and so on. That is to say, to some extent, it seems that Chinese tend to be more realistic or utilitarian than the westerners; their standards to choose a spouse attach much more importance to the material aspects. Finding a spouse is not for themselves, but also to win others' praise or approval. For example, if a Chinese woman find a spouse who is much shorter than her; when they walk side by side in the street, other people will feel strange by staring at them. Therefore most girls would like to associate with the boys with the height of more than $180 \mathrm{~cm}$ to achieve a feeling of security whereas most boys would like more to make friends with the pretty girls to satisfy their aesthetic and psychological requirements. As well as the personal natural condition, some other factors will be also taken into consideration such the family situation, the social status, the personal profession and the educational standard especially when the young persons ask their parents for some suggestion on their marriage. In most Chinese people's eyes, the marriage means the end of romantic love and the beginning of the ordinary life. Therefore, most parents want their daughters to marry the young man with a decent job and a stable income as well as a wealthy family and a better education.

But for most young westerners, when they choose their future life partner, what they care more about is whether the two persons have the similar hobbies, personality, interests and whether they love each other indeed rather than his or her height, appearance, age and social status. Even they never mind whether the other has had the marriage history or how many kids he or she has. That's because in most westerners' opinion a couple stands for a lifelong companion, and the common hobbies, interests, world view are more important than other things. Also, In the western countries the females usually have a better education, a stable job and 
a steady income; seeking the true love between the couple and a relative independent space has become their priority in face of the future marriage life; they can not care about the young man's family background and his economic situation even his educational standard, instead she tends to pays greater attention to her independence after the marriage. Maybe, as far as most westerners are concerned, it is an ideal state for a couple to still keep a relative independent personal space between each other after the marriage, meaning that both husbands and wives can keep their own privacy, arranging their social activities in their spare time freely or independently, and it is not necessary for the husband or the wife to care about the other's private business or take part in some social activities with the other's permission. Such a phenomenon is unimaginable in China where most parents will never permit their daughter to marry a poor guy without an apartment or a car even any accounts and it is absolutely a strange thing for the husband or the wife to take part in some social activities alone without telling it to the other necessarily. As well, the westerners also emphasize the religious belief and the personal character; they would like more to choose their spouses with the same religious belief and a better character. From their points of vies, marriage is the beginning of a happy life, and the romance is a continuing process in the whole marriage life.

\section{Spousal Relationship in the Marriage}

For most Chinese couples, husbands usually take up the dominating position in one family. Such a saying "Men are in charge of the outside affairs, women are in charge of the inside affairs" can reflects such a popular phenomenon which has lasted during the past thousands of years in the Chinese society. That is to say, as the breadwinner in a family, not only does the husband need to take the responsibility of earning the money to support the whole family, but also he has to deal with some other troubles or problems inside and especially outside the family. Therefore, since the ancient time, the husband has become the real master of one family who tends to make a decision about almost everything. On the contrary, the wife usually takes the responsibility of bringing up the children, looking after the husband and doing the housework at home. In the traditional Chinese culture, the wife is in the obedient position in a family all the time; and she has no right to decide some important things in a family instead she has to follow his husband. As well, when the couples take part in some social activities, the wife has to give consideration to her husband's face especially in front of his good friends or classmates with the appropriate words and the elegant manner. However, in the western countries the husband and the wife have the equal status in the family. In face of some important things it is not possible for the husband to make a decision by himself; he has to ask for his wife's opinion then they will decide what to do next together. That is, the wife has an adequate right to give her opinion on everything in the family. If the husband considers the wife's idea to be reasonable, it is not strange for him to follow his wife's words. In addition, in the western countries the husband isn't the only economic source of the whole family and more and more female go to find their own job in the society. Thus, it is common for more and more husbands to undertake the housework such as cooking, washing, cleaning the house and looking after the children etc. in their spare time.

Another difference of the spousal relationship between China and western countries is also shown in the family economy. In China, it is common for the couple to mix their respective property together after the marriage, and some larger items such as the house or the car have become their common property. In the family, it is common for the husband to hand in his salary or the bank card to his wife who will take charge of the daily expense. For example, while going shopping in the market, if the wife finds a shirt suitable for her husband, she will buy it for her husband without hesitation. However, if the family need to purchase some big items such as the household appliances, it is also necessary for her to ask for her husband's opinion or permission. But in the western countries, both the husband and the wife are independent economically. That is to say, neither of them has the obligation to spend the money for the other in the daily life and they tend to go Dutch on the family expense from the living costs to the purchase of some larger items. Such a thing is not imaginable in Chinese family. Supposing whatever a couple went out to do by going Dutch, there would be some problems appearing in others' eyes.

\section{AN ANALYSIS ON THE CAUSES LEADING TO THE MARRIAGE DIFFERENCE BETWEEN CHINA AND WESTERN COUNTRIES}

When talking about the reasons to bring about the marriage differences between China and the western countries, the following factors are responsible for them.

\section{A. Historical and Religious Factors}

As we know, China has been a feudalistic agricultural country for a longtime in the past thousands of years and the feudalistic hierarchical system has had a great influence on the marriage sense and the marriage customs from generation to generation. That's the reason why most Chinese parents want their children to marry a young person with the corresponding family background. Also in the ancient China, the female's status was inferior to the male either in the family or in the society, which still makes a great implication on the current marriage customs or the marriage life. Generally speaking, the Chinese marriage ceremony is conservative, traditional and fervent to show their eagerness for the happy life in the future. For example in the southern China, when the bride arrives at the groom's house, she needs to jump over the basin with the burning fire in it to expect that their married life will be prosperous and booming. And in many places there still exists the habit of teasing the bride and the groom on the wedding night, which also increases the fervent atmosphere of the marriage. There is a popular saying that the more the young couples are teased strongly, the happier they will be in the future. What's more, in some places it's popular for the young couple to serve the tea for the groom's parents to show their filial piety. In addition, most Chinese believe that it is very important for the young couples' birthdates to correspond each other, so before making a decision about a marriage, the parents tend 
to ask for a fortune-teller to see if the young couples' birthdates are suitable to each other or not.

On the contrary, most western countries belong to the capitalistic countries and most people believe in Christianity, pursuing the personal value of freedom, equality and independence, which also has a great effect on the western marriage customs and the marriage sense. Totally speaking, the western marriage is simple, open and solemn, full of the atmosphere of quietness and romance. Because most westerners belong to Christians, in most westerners' opinions all of them are the children or grandchildren of the God. Therefore their marriage must be witnessed by the god and hosted by the priest. That's the reason why most western marriages are usually held in the church with the young couple making a promise in face of the god.

\section{B. Cultural Value Factors}

It is well known that China is an old country with the history of over five thousand years. During the past thousands of years, Confucianism has had such a deep influence on every aspect of the Chinese society that it has rooted in most Chinese's mind deeply. Today, Confucian still plays a very important role in our work and life, which has become a guideline for us to work and get along well with the people around us. As a result, it is unavoidable for the Chinese marriage to be influenced by Confucian thoughts. Actually, such a saying as "There are three forms of unfilial conduct of which the worst is to have no descendents" is just a reflection of Chinese traditional filial piety. As far as most Chinese are concerned, it is a specific representation of the individual filial piety as well as a feeling of social responsibility for the young persons to get married and generate their descendents. So, when a young man is more than thirty years old but stilled unmarried, not only will he or she be urged to get married by his or her parents, the people around them will also consider them to be unusual or strange.

However in the western countries, such cultural values as freedom, independence and equality have influenced the westerners in the whole society. From the westerners' point of view, marriage is just their own business which has nothing to do with their families or other people around them. What they pay great attention in the marriage is whether they love deeply each other. That is to say, the faithful love is the sole standard to decide whether they will get married or go on living together forever. With the sincere love, the tow young person can manage to come together no matter what difficulties they have to go through, but the disappearance of the love between the couples means that it is time for them to say goodbye. The influence of the cultural value on the western marriage also reflects on the conjugal relationship after the marriage in the western countries. Because of the influence of the cultural values such as independence and equality, it is not so difficult for us to understand why both the husband and the wife share the same decisive right as well as their respective independent space in one family.

\section{Family Environmental Factors}

In the western countries, most people hold the idea that the children are independent individuals and the parents can't control their conducts. Therefore, in any case, it is necessary for the parents to listen to the children's opinion, understanding and respecting them. The western parents still pay great attention to their children's growth, trying to develop the children's ability to live independently and adapt to different environment, but they neither impose their opinion on their children nor interfere with their business. As a result, for most western young persons, it is not necessary for them to make an adequate preparation for their married life by purchasing a big house and a magnificent car as well as some necessary household appliances. In addition, most western parents never care about whether their respective family is wealthy or prestigious and whether the two families can match each other; they never help their children with their marriage economically even if they have such ability. Most young men needn't worry about purchasing houses and cars; as long as they love each other, they can get married and form a family. It is a common phenomenon for the young couples to live in the rented house after they get married, depending on themselves completely. Usually through many years of hard work they will set about purchasing the house and settling down in a city with adequate savings.

In contrast to the western parents, most Chinese parents care about their children's marriage too much. In China it is common for the parents to make a blind date in place of their children in order to find a satisfying son-in-law or daughterin-law, making sure that their children can live a happy life after the marriage. If their children make a friend, when deciding to get married, it is necessary for the young couples to get their parents' approval. Only when the young couples have a stable job and a steady income, as well as a big house even a car, will the parents agree to their marriage. That's because in most Chinese parents' eyes, it is their responsibility to bring up their children, making the children receive a good education and helping them to choose a good husband or wife for ensuring their future happiness.

\section{THE TENDENCY OF MUtUAL INTEGRATION AND \\ FUSION BETWEEN CHINESE AND WESTERN MARRIAGE}

With the development of the society and the increasingly deepening of the globalization, during the past few decades, the Chinese marriage and western marriage has the tendency to integrate and fuse with each other. In China, nowadays, more and more young men tend to select a diamond ring at the cost of three to five thousand yuan in order to wear the hand of their sweethearts by themselves on the wedding night. Also it has become a fashionable trend for most young couples to take the wedding dress photos both in the rural area and in the big city, and the cars with colorful decoration have become the popular traffic tools for the wedding ceremony just like the western marriages. On the wedding day, the bridegroom usually wears the western wedding suit with a delicate red flower on the chest while the bride tends to be in the white wedding dress just with the bridal veil on the head. When holding the wedding ceremony, lots of procedures which appear in the western marriage have been brought in the Chinese wedding ceremony, such as the marriage witness's making speech, the young couple's 
making a wedding promise and exchanging their wedding rings as well as the two young persons' pouring the champagne tower with red wine or champagne. In the past, these customs were just important parts of the western marriage, but nowadays they have become the indispensable procedures in the modern Chinese wedding, ceremony which further verifies the mutually integrating tendency of the Chinese and western marriage.

Also, with the increase of the international exchange, more and more westerners have come to China for work or study, even some of whom have settled down in China for a long time. Meanwhile, more and more Chinese young men have gone abroad to work or study for making a further education. Consequently, the Chinese traditional culture has achieved a further spreading in the western countries; more and more westerner young men have begun to learn and recognize the Chinese traditional culture. Therefore, there are more and more western young men holding the Chinese traditional marriage both abroad and at home, which is another convincing representation for the Chinese marriage and the Western marriage to influence and integrate mutually.

\section{CONCLUSION}

Though the two different kinds of marriages had taken the trend to fuse each other, however, because of the cultural and national difference, the individualization of the marriage is still an important feature and a main developing tendency. It is the popular marriage sense for the young men living in the modern society to enjoy different living style and highlight their conspicuous individuality. In one word, with the development of the economy and the progress of the society, the future marriage is certain to be convenient, colorful and individualized. More and more young men will try to hold an elegant, romantic and very spectacular marriage with their imagination and creativity.

\section{REFERENCES}

[1] Lin Xuecai. A Tentative Analysis on the Difference of the Marriage Sense Between China and America. Journal of Henan Textile College. 2002 (2).

[2] Li Guimei. A Brief Discussion on the Base of the Chinese and Western Modern Marriage. Studies in Ethics. 2006 (4).

[3] Sun Jianjun. The Difference of the Marriage Sense Between Chinese and the Western Culture. Journal of Liaoning Economy Management for Carders. 2007 (4).

[4] Xia Qiaohua. The Comparison of the Marriage Culture Between China and America as well as Their Cultural Integration. Journal of Tianjin Modern Enterprise Management College for Staff and Workers. 2005 (2).

[5] Zhao Xu. \& Jin Lijuan. Chinese and Foreign Folklore. Tianjin: Tianjin University Press. 2011 (166-179).

[6] Zhang Liyu. \& Chen Luoyu. A Comparative Study Between Chinese and Western Folklore. Beijing: China Social Sciences Press. 2016 (137-175). 